Original Research Paper

\title{
Basis of Guidelines for Structural Design and Thermal Assessment of Buildings with Hybrid CLT-Glass Elements
}

\author{
${ }^{1}$ Nikola Perković, ${ }^{1}$ Vlatka Rajčić, ${ }^{2}$ Chiara Bedon, ${ }^{1}$ Jure Barbalić and ${ }^{3}$ Roko Žarnić \\ ${ }^{I}$ Faculty of Civil Engineering, University of Zagreb, Zagreb, Croatia \\ ${ }^{2}$ Department of Engineering and Architecture, University of Trieste, Trieste, Italy \\ ${ }^{3}$ Faculty of Civil and Geodetic Engineering, University of Ljubljana, Ljubljana, Slovenia
}

\author{
Article history \\ Received: 19-02-2020 \\ Revised: $16-03-2020$ \\ Accepted: 07-04-2020 \\ Corresponding Author: \\ Chiara Bedon \\ Department of Engineering and \\ Architecture, University of \\ Trieste, Trieste, Italy \\ Email: chiara.bedon@dia.units.it
}

\begin{abstract}
Facade elements are known to represent a building component with multiple performance parameters to satisfy. Among others, "advanced facades" take advantage from hybrid solutions, like the assemblage of laminated materials. In addition to enhanced mechanical properties that are typical of optimally composed hybrid structural components, these systems are energy efficient, durable and offer lightening comfort and optimal thermal performance. This is the case of the structural solution developed in joint research efforts of University of Zagreb and University of Ljubljana, within the Croatian VETROLIGNUM project. The design concept involves the mechanical interaction of timber and glass load-bearing members, without sealing or glued glass-to-timber surfaces. Laminated glass infilled timber frames are in fact recognized as a new generation of structural members with relevant load-carrying capacity (and especially the enhancement of earthquake resistance of framed systems), but also energy-efficient and cost-effective solutions. In this paper, brief guidelines for the optimal structural design of glass infilled Cross-Laminated Timber (CLT) framed systems are presented. A special focus is then dedicated to the thermal performance assessment of these innovative CLT-glass facade modules under ordinary operational conditions. Finite Element numerical models of single elements are developed to reproduce a full-size mock-up building. The actual thermal performance is thus carried out with the support of continuous ambient records. The numerical results show that the CLT-glass composite facade system can be efficient and offer stable performances, in line with national and European standards requirements.
\end{abstract}

Keywords: Cross-Laminated Timber (CLT), Laminated Glass, hybrid Facade Element, Design Guidelines, Thermal Performance

\section{Introduction}

In the last decade, there has been a progressive development of load-bearing building components especially beams - composed of timber and glass (Cruz and Pequeno, 2008; Blyberg et al., 2014; Premrov et al., 2014; Rodacki et al., 2019). Even more attention has been dedicated to curtain wall applications, where wide surfaces must be covered and enhanced load-bearing performances/deformation capacities must be satisfied, especially under extreme design loads such as earthquakes (Neubauer, 2011; Ber et al., 2013). In most of the cases, however, the explored solutions and design applications still involve a continuous (adhesive and/or mechanical) connection between a given timber frame and the glass infill panels (Fig. 1).

Among others, it was shown through the Croatian VETROLIGNUM project that structurally efficient Cross Laminated Timber (CLT)-glass hybrid systems can be used in buildings, taking advantage of frictional contact interactions between glass and timber only (www.grad.unizg.hr/vetrolignum). The load-bearing efficiency, as well as structural stability and usability of the novel design concept was explored in (Rajčić and Žarnić, 2013; Antolinc, 2013; Žarnić et al., 2020). 


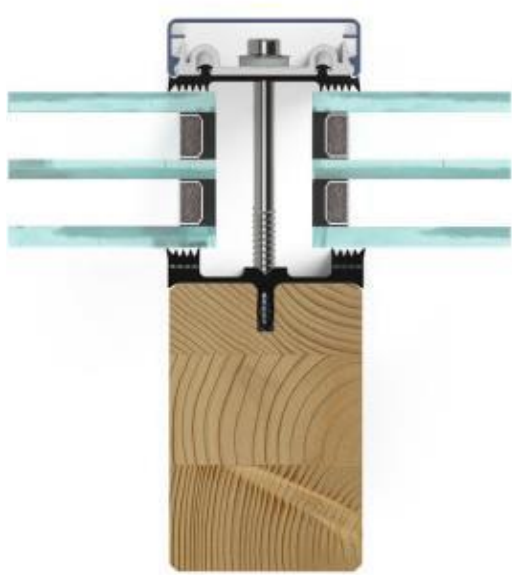

(a)

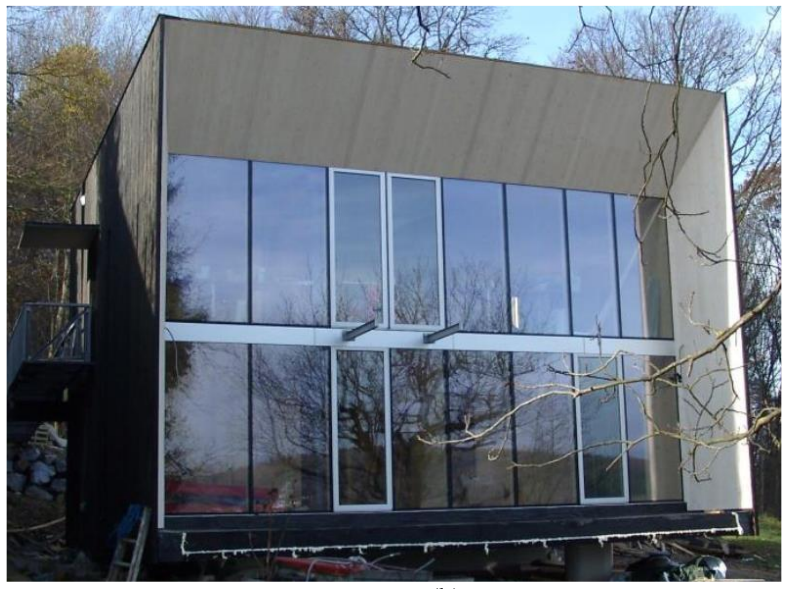

(b)

Fig. 1: Examples of timber-glass facade solutions in buildings: (a) typical cross-section of curtain wall detail (www.stabalux.com); (b) adhesively bonded framed panels according to (Neubauer, 2011)

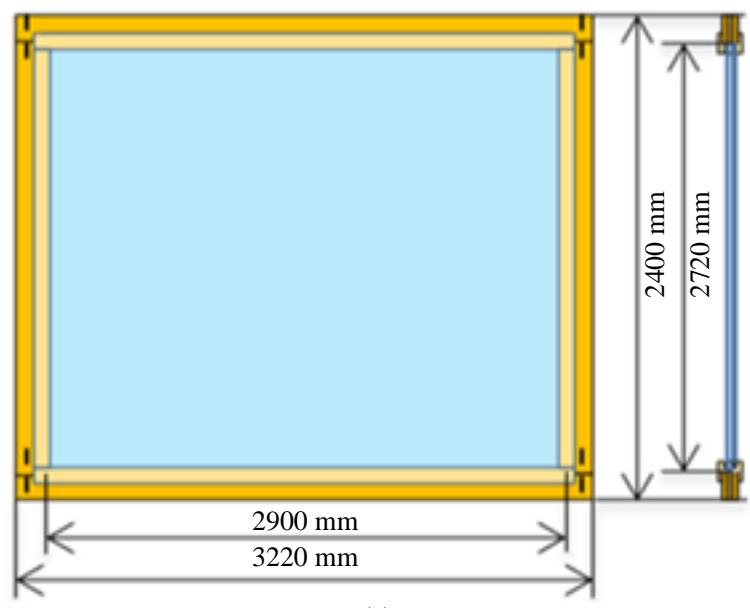

(a)

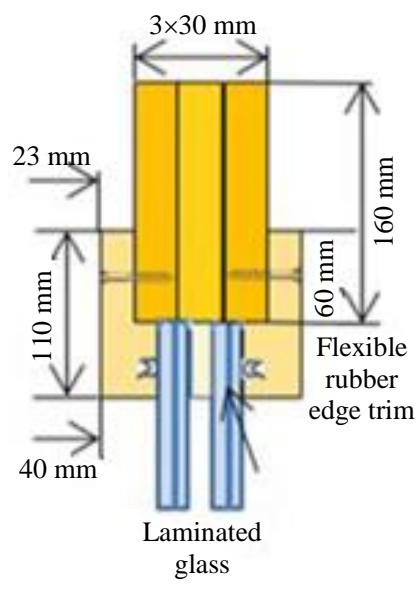

(b)
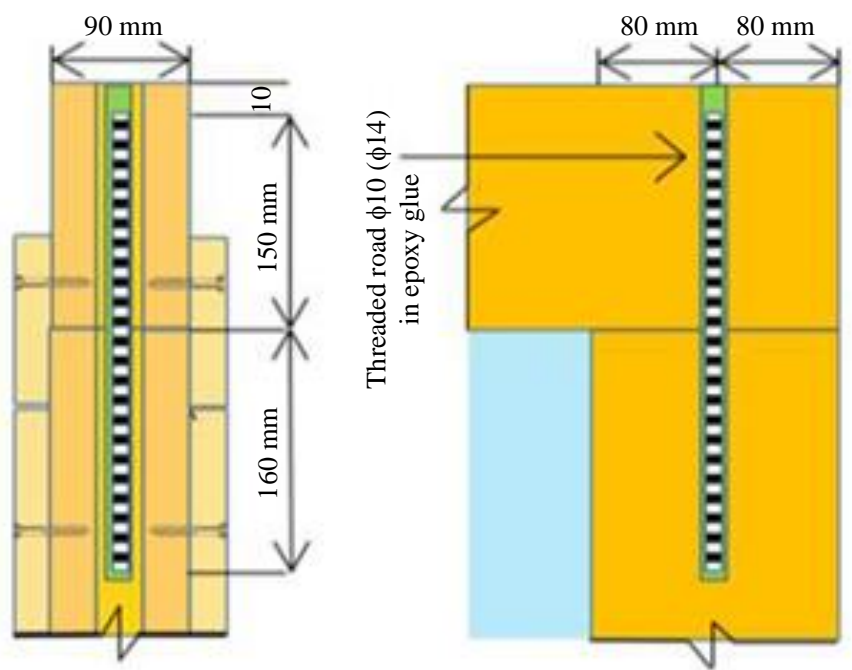

(c)

Fig. 2: Full-scale CLT-glass facade element: (a) front view and (b) CLT-to-glass frame contact detail (cross-section), with (c) typical timber frame corner joint. Reproduced from (Žarnić et al., 2020) with permission from Elsevier, Copyright $@$ license number 4800830346295, April 2020 
Based on Fig. 2, the reference facade element consists of two double laminated glass sections composed of tempered glass layers (10 mm thick each) bonded by $1.6 \mathrm{~mm}$ thick Ethylene-Vinyl Acetate (EVA) interlayers. The double laminated glass panels are positioned so as to realize an interposed cavity $(s=12.8$ $\mathrm{mm}$ its thickness), that is sealed by a continuous, flexible rubber edge trim (Fig. 2b), while CLT timber members are used to create a supporting timber frame. The VETROLIGNUM system, as such, takes advantage of the optimal mechanical interaction of two relatively recent load-bearing materials, CLT and glass.

Differing from other facade solutions that take advantage of mechanical or adhesive connections between the load-bearing members (Bedon and Santarsiero, 2018), a key role is assigned to contact mechanical interactions only. Following Fig. 2b, linear slots are realized in the CLT framing members (with lateral purlins), so as to accommodate the glass panels. Possible relative deformations of the glass panels with respect to the CLT members are always allowed, given that no adhesives or other mechanical connections are used. In addition, a certain energy dissipation through friction between the glass and the CLT surfaces in contact (i.e., Fig. 2b) can be ensured.

Among the various types of systems and structures of wooden buildings (panel and frame systems, etc.), CLT is commonly recognized as an innovative plate-shaped product, with a laminated structure able to offer excellent physical and mechanical properties (Jeleč et al., 2018). Due to its high stiffness and in-plane and out-of-plane bearing capacity, it is most often used in the form of wall or floor panels. Favourable environmental, aesthetic and energy properties further enhance its intrinsic qualities (Bejtka, 2011). On the other hand, glass as a structural material is widely used in a multitude of loading and boundary conditions. Even though several European standards apply to glass products (EN 12543-2; prEN 13474-2), an harmonized and exhaustive Eurocode for the load-bearing design of glass structures in Europe is still in preparation (Feldmann and Di Biase, 2018; CEN/TC 250, 2019a; 2019b) and national guidelines for dimensioning or verification of glass elements are available (see for example (CNR-DT 210/2013; Buildings Department, 2018; Feldmann et al., 2014). Further open issues for the design of load-bearing glass elements are represented by elevated thermal exposures and related effects on the mechanical material properties (Bedon, 2017; Bedon and Louter, 2018; Kozlowski et al., 2018; Sjöström et al., 2020).

Besides the need of optimal structural capacities for these innovative solutions, however, a facade element as a whole should fulfil a multitude of performance requirements, including the thermal response, energy efficiency, etc. In this research paper, a special care is dedicated to the analysis of VETROLIGNUM hybrid elements under ordinary ambient conditions.

\section{Brief Guidelines of Structural Design}

A decade-long investigation on the structural characteristics and typical response mechanism of "glass infilled CLT frames" (Rajčić and Žarnić, 2013; Antolinc, 2013; Žarnić et al., 2020) delivered appropriate data for the development of design procedures and guidelines. These rules apply to novel structural systems constructed with, or existing structural systems upgraded by novel hybrid facade components, for buildings located in both non-seismic and seismic-prone areas.

In general, structural systems can be designed and assessed by means of simple analytical models, or based on detailed and more sophisticated analysis procedures. In both cases, the mechanical properties of constituent structural components represent a key input data. They should be defined starting from material and geometry characteristics, followed by numerical modelling and prediction of their structural response to vertical and lateral loads. While calculation of the vertical loadbearing capacity is generally less demanding, the response assessment to reverse lateral loading typical for earthquake or strong lateral wind actions needs more refined methods. On the other side, understanding the structural system response to lateral loading makes easier the development of efficient structural computational models. Basically, there two limit response mechanisms can be expected, namely:

a) Shear story mechanism (usually assumed as a reference condition for low rising unreinforced masonry structures)

b) Bending mechanism (that is typical of reinforced concrete or steel framed structures)

The herein presented hybrid structural component has the advantage that can be used for the construction of low and medium-height buildings which behave as shear buildings or bracing elements for bending framed structures. Such an outcome is also in line with (Žarnić et al., 2020), where an insight was presented on key experimentally obtained data that are needed for the development of structural models for both the reference applications.

Brief guidelines for development of a typical structural model to be used for the efficient design and the lateral response assessment of shear buildings is thus first presented. As known, a shear building is defined as a structure in which there is no rotation of horizontal sections, at the level of the floors. In this respect, the deflected building preserves most of the features of a cantilever beam deflected by shear forces only. To 
accomplish such a deflection in a given building, the basic assumptions require that:

- The total mass of the structure is concentrated at the levels of the floors

- The girders on the floors are infinitely rigid as compared to the columns

- The deformation of the structure is independent of the axial forces present in the columns

The first assumption transforms the original problem of a structural system with components according to Fig. 2, with an infinite number of Degrees of Freedom (DOFs, due to distributed mass), to a structure with many DOFs as the lumped masses at the floor levels.

Learning from the design and response assessment of masonry structures, where the typical shear mechanism to lateral loads is well-recognized, a simple procedure for design (based on structural macro-elements) can be adapted to buildings including glass infilled CLT frames, in combination with CLT shear panels.

To develop a reliable structural macro-element, however, several mechanical characteristics must be first properly calculated, based on structural mechanics principles and with the support of experimental investigations (for macro-element calibration and validation). In this document, results of experimental investigations in (Žarnić et al., 2020) regarding the reverse cyclic lateral performance of glass infilled CLT frames represent the main source of input data.
The typical in-plane raking setup from is recalled in Fig. 3 (upside-down laboratory configuration) and assumes rigid restraints for the base CLT member (i.e., representing the foundation for the wall system), while imposing a cyclic inplane lateral load to the top. For some of the tested specimens, the effects of distributed vertical loads (25 $\mathrm{kN} / \mathrm{m}$, as in the case of 2-story buildings) were also taken into account during the cyclic loading stage. As far as the rotations of horizontal CLT members were constrained, the chosen setup was found to be in close correlation with real building applications and accounts for the presence of vertically deformable floors or frame beams.

The design response of the macro-element in Fig. 3 can be thus rationally represented by a centrally symmetric bilinear diagram (i.e., Fig. 4), which is characterized by three key parameters:

- $\quad$ Yielding lateral load $\left(F_{y}\right)$

- Effective stiffness $\left(K_{e f f}\right)$ or yielding story drift $\left(\Delta_{y}\right)$

- Ultimate story $\operatorname{drift}\left(\Delta_{u}\right)$

In the figure, as an example, experimental outcomes for two full-size specimen according to Fig. 2 are compared (being selected from the series of 20 specimens in total). Their difference lies in the diameter of glued-inrods for the corner joints (10 $\mathrm{mm}$ or $14 \mathrm{~mm}$ respectively). Besides the high sensitivity of cyclic responses to the joint detailing (Fig. 4a), a rather close correlation can be found in Fig. $4 \mathrm{~b}$ between the experimental backbone curves and the corresponding bi-linear models.

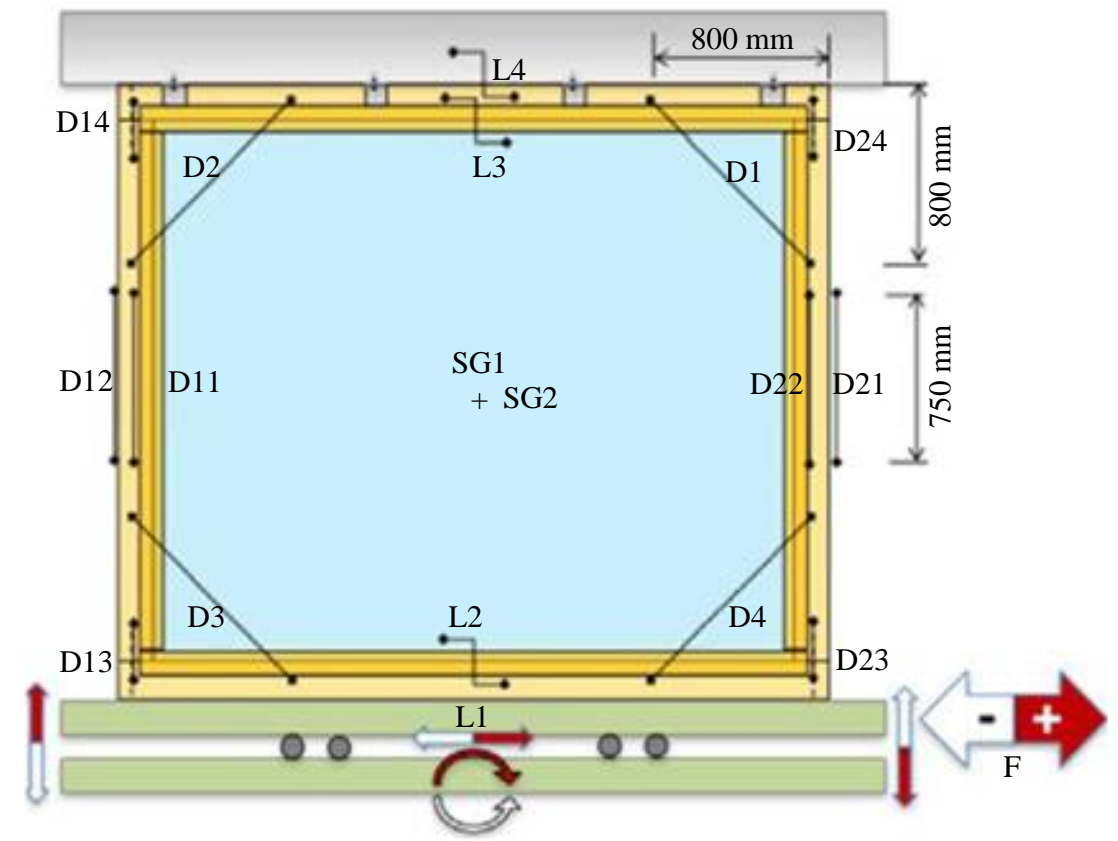

Fig. 3: Reference in-plane raking test setup for the mechanical characterization of CLT-glass hybrid facade elements (upside-down laboratory configuration). Reproduced from (Žarnić et al., 2020) with permission from Elsevier, Copyright $\odot$ license number 4800830346295, April 2020 


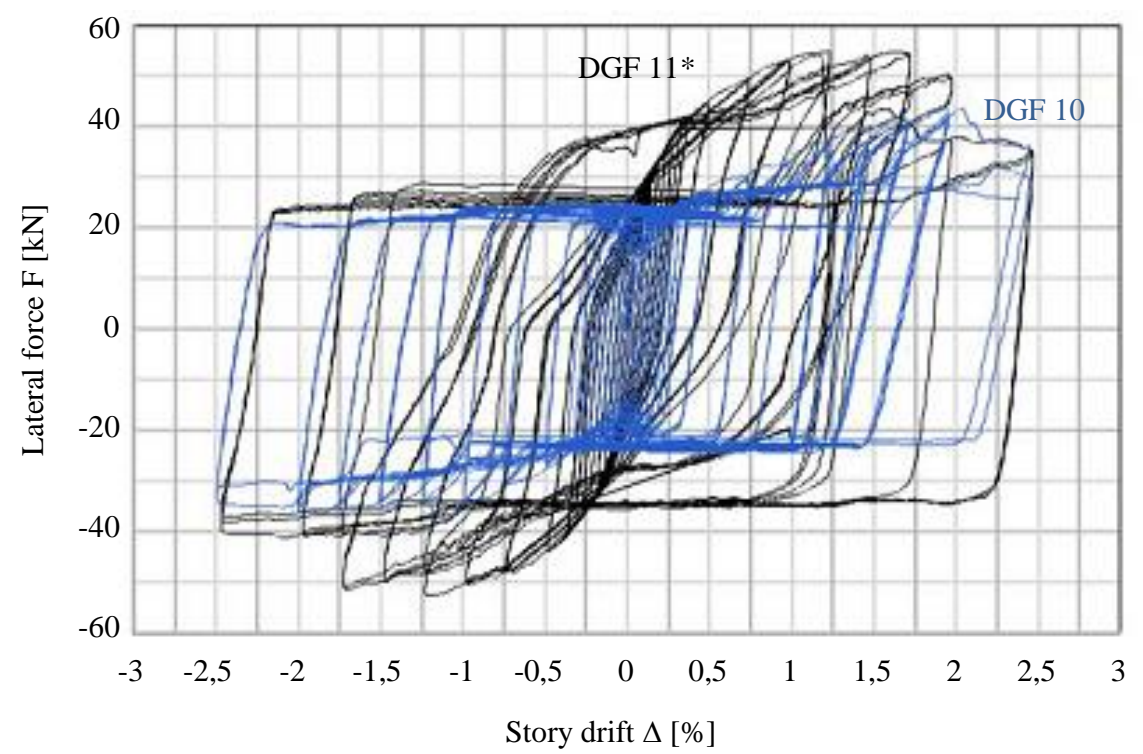

(a)

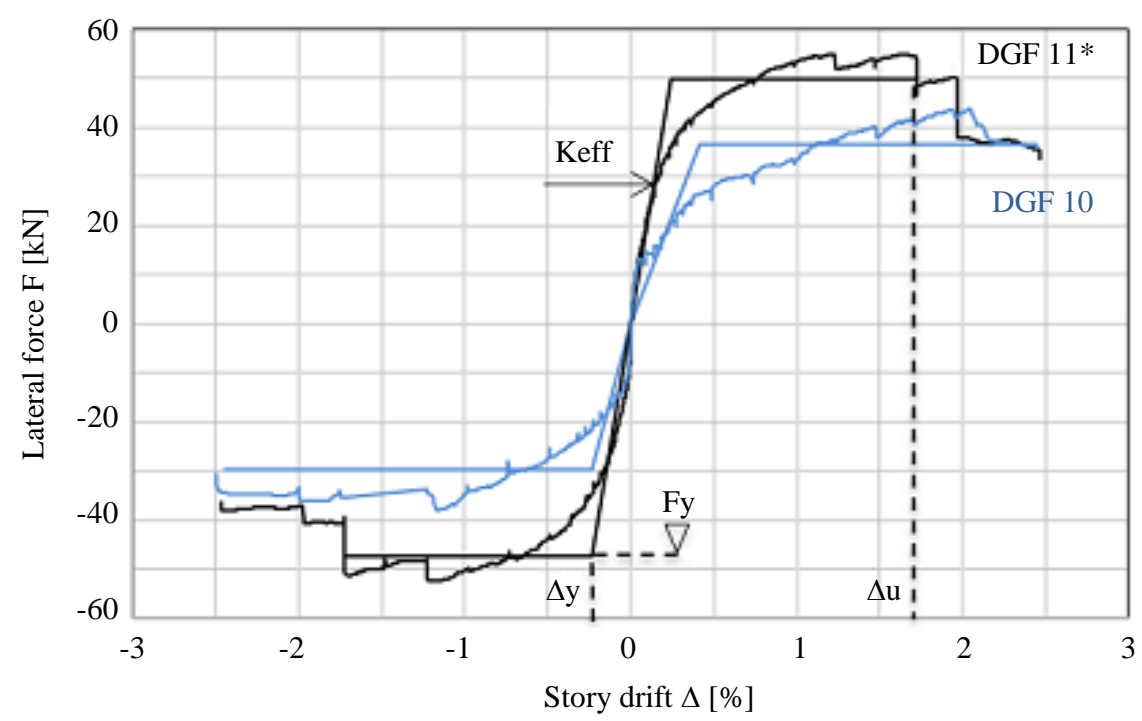

(b)

Fig. 4: Response of glass infilled CLT frames with $10 \mathrm{~mm}$ ("DGF 10" specimen) or $14 \mathrm{~mm}$ joint rods ("DGF11*" specimen) under cyclic in-plane lateral loads (with $25 \mathrm{kN} / \mathrm{m}$ of imposed vertical load). Reproduced from (Žarnić et al., 2020) with permission from Elsevier, Copyright@ license number 4800830346295, April 2020

Certainly, through the overall design process, few key aspects are mandatory to guarantee efficient loadbearing performances.

Glass-CLT hybrid components according to Fig. 2 must be first designed to be robust against the action of vertical loads induced by upper structural and nonstructural elements. The proposed cross-sectional size for the CLT studs in Fig. $2(90 \times 160 \mathrm{~mm})$ was in fact selected following this rule. However, it is clear that particular structural configurations could require even more robust CLT sections, that should be checked towards the conventional procedures given by standards for timber structures.

Another key detail is represented by glued-in-rods, that are used to connect the lintels and studs of the timber frame (i.e., Fig. 2c), thus forming the dowel of corner joints that behave as a "bearing type" (due to constrained rotation of the frame lintel). As usual, the shear resistance of these joints can be calculated using the traditional load-carrying capacity expressions 
derived from the Johansen yield theory, as it is in the Eurocode 5 for timber structures (EN 1995-1-1, 2004). The applicability of such a calculation approach was already verified by the experimental results reported in (Rajčić and Žarnić, 2013; Žarnić et al., 2020), in the case of in-plane laterally loaded frames.

According to Fig. 4, for example, it can be perceived that as far as the corner joint resistance increases (i.e., the rod size increases), an enhanced in-plane lateral strength for the overall system can be also expected. Such an effect derives from the composite action of glass and CLT members and it is thus strictly related to the corner joints capacity, as well as to their interaction with design loads. As much as these joints are efficient, the percentage of lateral load that can be carried-out by friction between the CLT lintels and glass contact surfaces further increases. A more detailed analysis of extended test results reported in (Žarnić et al., 2020), proved that a reference value of $1 \%$ for the increase of the frame lateral strength $F_{y}$ can be conservatively taken into account for each $1 \mathrm{kN} / \mathrm{m}$ of imposed vertical load. In other words, as far as the corner joints do not fail prematurely, an imposed vertical load of $25 \mathrm{kN} / \mathrm{m}$ for a given CLT-glass façade element according to Fig. 2 can increase the corresponding in-plane lateral resistance up to $25 \%$, due to friction.

The second key parameter in Fig. $4 \mathrm{~b}$ is then represented by the effective stiffness $\left(K_{e f f}\right)$, that should calculated on the basis of structural mechanic principles, by modelling the CLT-glass facade element as a frame braced with wide struts. In addition, the local deformations in dowel joints should be properly taken into account (where the glued-in-rods are pressed onto the timber, in direction of the in-plane lateral force). For practical reasons, however, the effective stiffness can be defined from the lateral displacement of the glass infilled frame, increased by the additional displacement due to local deformations of timber (in the region of glued-in-rods). According to past experiments, it was proved that the local deformations of timber contribute roughly to $50 \%$ for the yield story drift $\Delta_{y}$. The amount of the imposed vertical load and the size of the joint dowel, in addition, directly affect the story drift capacity (ultimate story drift $\Delta_{u}$ ). Both the reference drift values that define the well-known ductility of the CLT-glass system:

$\mu=\frac{\Delta_{u}}{\Delta_{y}}$

are thus sensitive to these details.

Another important characteristic for systems according to Fig. 2 is the relevant stiffness degradation due to cyclic lateral loading. The relation between the stiffness $K$ at a given stage of the mechanical response and the effective stiffness $\left(K_{e f f}\right)$ was obtained in (Žarnić et al., 2020) from the postprocessing of experimental investigations, that is:

$\frac{K}{K_{e f}}=0.67\left(\frac{\Delta}{\Delta_{y}}\right)^{-0.76}$

where, $\Delta$ is the story drift at the selected stage of the overall in-plane lateral response.

Finally, relevant aspects that should be carefully taken into account (as it is for most of the structural components in use for construction of buildings in seismic prone areas) are represented by:

- Strength degradation due to subsequent repetitions of story drifts

- Relative story drift capacity

- Energy dissipation capacity

All these parameters, see (Rajčić and Žarnić, 2013; Žarnić et al., 2020), were observed in a favourable range of variation. Experimental investigations, more in detail, proved that the expected strength degradation due to three subsequent lateral loading cycles is very low, in comparison to other types of structural components (masonry or reinforced concrete). The analysis of hysteresis responses also proved a relatively high level of energy dissipation capacity, as expressed both with cycle-by-cycle experimental comparison between the amount of input and dissipated energy, or also by estimating the equivalent viscous damping ratio for the tested specimens, thus providing a further confirmation of the structural efficiency for the proposed design concept.

\section{Scope of the Energy Efficiency Research}

Testing the energy performance assessment of innovative load-bearing solutions and components for buildings represents a crucial step of research and design. The facade enclosure is in fact a key factor in defining the energy rating and class of the entire building it belongs, as well as the thermal comfort of occupants. Accordingly, it must satisfy specific performance limits (EU 2010/31).

This is also the case of the CLT-glass facade element herein explored and represents a strategic design step for the assessment/optimization of novel envelopes in general (Zobec et al., 2002; Aldawoud, 2017; Bedon, 2017; Planas et al., 2018).

Following the EN ISO 13788 standard, for example, one of the performance parameters to assess is the thermal quality, that can be generally expressed 
by the well-known temperature factor at the internal surface $f_{\text {Rsi }}$.

The simplified calculation approach presented in EN ISO 13788 suggests that:

$$
f_{R s i}=\frac{T_{s i}-T_{\text {out }}}{T_{\text {int }}-T_{\text {out }}}
$$

with $T_{s i}$ the temperatures of internal wall surface, Tint the internal air temperature and $T_{\text {out }}$ external air temperature respectively. The internal surface temperature strictly depends on the features of the structure to investigate and can be sensitive especially to thermal bridges causing multidimensional heat flow. Another relevant parameter is represented by the internal surface resistance, that depends on convection and radiation coefficients, on the air movements in the room, on the air and surface temperature distribution in the room and on the surface material properties. Accordingly, refined and time-consuming numerical models of a given room/building as a whole would be necessarily required, to account for several aspects, like the thermal resistance of envelopes, the environmental temperature, the air distribution, the room geometry, etc. However, both simplified calculation methods and input values recommended by existing guideline documents can be used for preliminary estimates.
The temperature factor $f_{\mathrm{Rsi}}$ should be generally close to the unit, so as to represent optimally insulated buildings. In any case, to ensure the occurrence of mould growth and surface condensation in dwellings, the temperature factor is generally accepted when $f_{\mathrm{Rsi}} \geq 0.75$. Besides the general calculation approach in the EN ISO 13788 provisions, moreover, a series of National guidelines are available in several countries to recommend minimum limit values for $f_{\mathrm{Rsi}}$. These are in the range of $f_{\mathrm{Rsi}}$ $\geq 0.52$ (France), or $f_{\mathrm{Rsi}} \geq 0.65$ (Netherlands) and $f_{\mathrm{Rsi}} \geq 0.7$ for Germany (Kalamee, 2006).

Besides the envelope features, however, the reference $f_{\mathrm{Rsi}}$ minimum value is related to climate conditions and climate changes. Accordingly, new building envelopes and systems should be able to properly satisfy a set of thermal performance requisites that become even mor restrictive as far as the climate conditions modify. Following a past Köppen's classification for the Croatian region ((Zanor et al., 2005) and Fig. 5a), for example, the largest national part was detected to have a moderately warm rainy climate, with mean monthly temperature in the coldest month of the year above $-3^{\circ} \mathrm{C}$ and below $18^{\circ} \mathrm{C}$. The highest mountain regions only (with $>1.200 \mathrm{~m}$ of altitude) were recognized to have a snowy, forest climate, with the mean temperature in the coldest month below $-3^{\circ} \mathrm{C}$. In the continental mainland, finally, the hottest month of the year was usually detected in a mean temperature lower (and in the coastal area higher) than $22^{\circ} \mathrm{C}$.

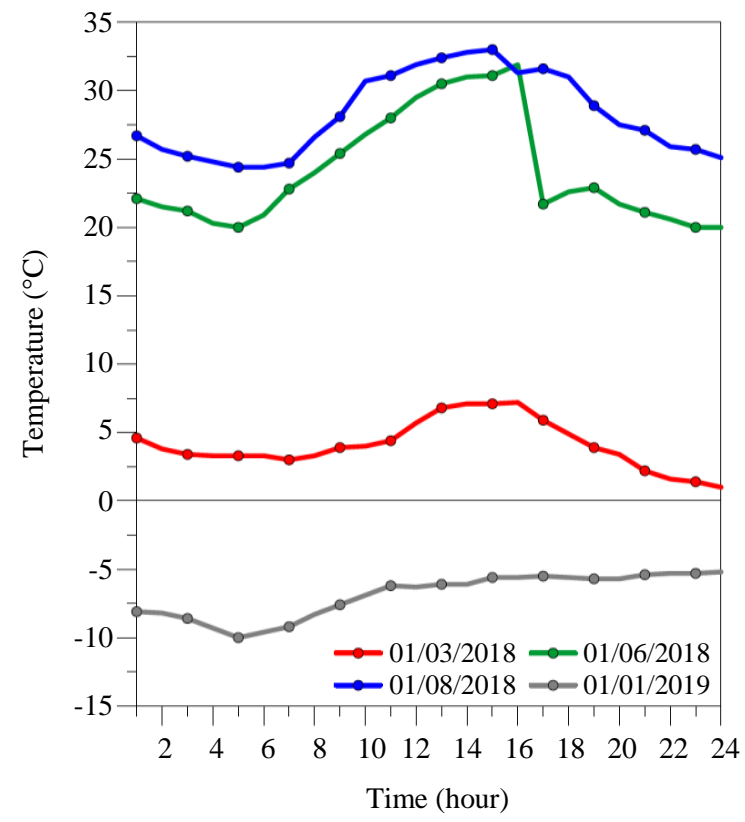

(b)

Fig. 5: Ambient conditions: (a) Köppen's classification (2003 proposal) for the Croatian climate (Zanor et al., 2005) and (b) meteorological data (selection) from the VETROLIGNIUM framework (University of Zagreb) 


\section{Mock-up Building and Experimental Investigation}

\section{Live-Lab Testing Facility}

For the purpose of testing the thermal and physical characteristics of the CLT-glass hybrid system, a mock-up building (herein called "Live-Lab" facility) was constructed in the framework of the VETROLIGNUM project.

The facility, Fig. 6, was assembled in 2018 and actually consists of a full-size, single space characterized by plan dimensions $B=3.22 \mathrm{~m} \times W=$ $2.80 \mathrm{~m}$, with $H=2.8 \mathrm{~m}$ the height. The $3 \mathrm{D}$ building is currently located on the roof of a single story building (not accessible to public), at the University of Zagreb, Faculty of Civil Engineering.

The main transversal facades of the mock-up building consist of full-size CLT-glass modules for the East and West envelopes, according with Fig. 6. Geometrical details for glass and timber elements were defined to reproduce the reference configuration schematized in
Fig. 2. Moreover, the mock-up was constructed in a way that enables (i.e., for re-use in future mock-up configurations) the removal of the CLT-glass facade elements and the introduction of solid timber walls (detail of Fig. 6). The geometry and detailing of the other building components (longitudinal walls, floor and roof) were defined based on the expected load-bearing capacity (preliminary static calculations under ordinary loads). Prefabricated panels for the traditional construction of wooden houses were used, in order to obtain a lightweight framework system inclusive of Oriented Strand Boards (OSB) panels and thermal insulation layers. The South longitudinal wall was obtained by a full-scale single panel. On the opposite side, otherwise, the North wall was composed of two half partitions, so as to possibly account for the presence of a door (Fig. 6a). Two adjacent panels, mechanically interconnected, were used for the floor. Regarding the single-pitch roof, finally, the latter consisted of ceiling supporting attic panels and roof beams.

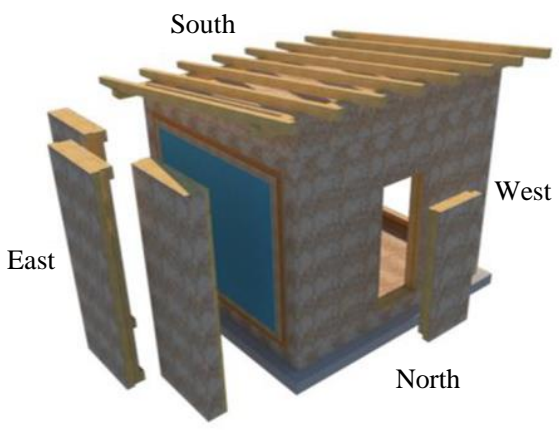

(a)

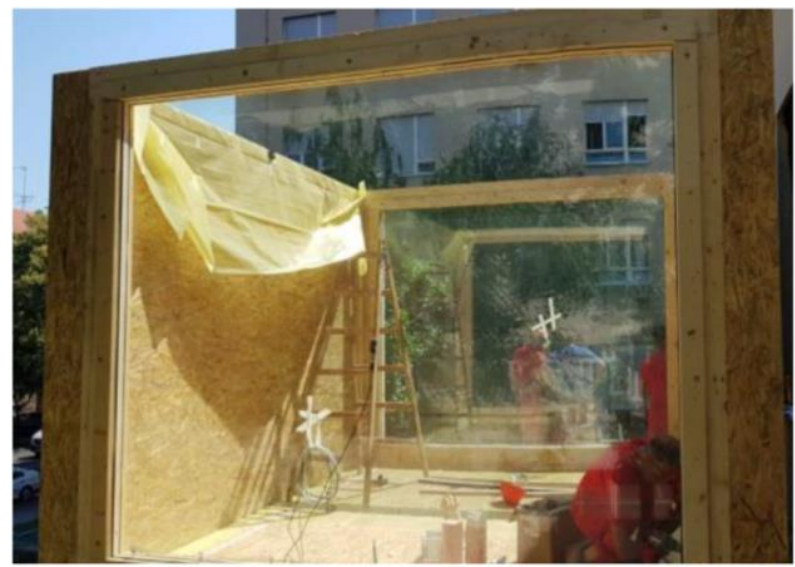

(b)

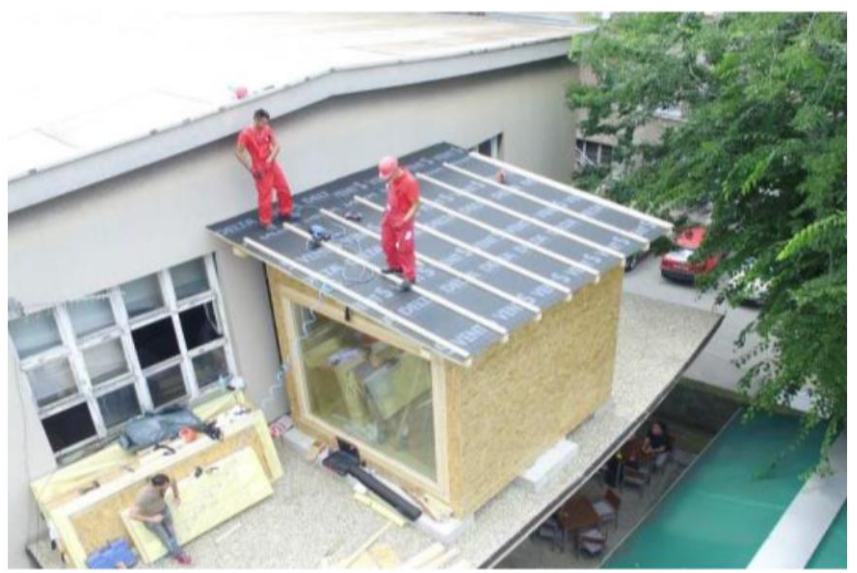

(c)

Fig. 6: Assembly process for the Live-Lab facility at the University of Zagreb, Croatia (installation during 2018): (a) general concept; (b) CLT-glass facade elements and (c) roof 


\section{Materials}

All the prefabricated panels are composed of $\mathrm{KVH}$ solid structural timber that according to EN 338: 2016 provisions is marked by a resistance class C24 (spruce) and dried up to $18 \%$ of humidity.

Between the timber frame members, an insulation material is also used (multi-purpose NaturBoard VENTI mineral wool boards, $600 \times 1000 \mathrm{~mm}$ (200 mm thick), by KNAUF Insulation (www.knaufinsulation.hr/proizvodi0/naturboard-venti). A Delta-Dawi GP steam barrier is also installed inside the panel (above the insulation) and sealed with appropriate straps (https://www.doerken.com/int/products/pitchedroof/delta-dawi-gp.php).

On both the sides, the timber frames are finally lined with OSB elements $(125 \times 2500 \mathrm{~mm}$ their size, $18 \mathrm{~mm}$ in thickness) with an impregnating finisher, to ensure water resistance. All the joints are made of zinc-plated bolts or nails, whose detailing was derived from preliminary static calculations.

\section{Energy Efficiency Assessment}

\section{Testing Program}

The tests and experimental measurements for the 3D building prototype of Fig. 6 were conducted in one-year cycle, hereinafter referred to as "Cycle 1" (September 2018 - August 2019). The latter, in the framework of the ongoing VETROLIGNUM project, will be followed by further field measurements. As such, the Cycle 1 was defined so as to include:

- Indoor Relative Humidity (RH) and temperature

- Outdoor RH and temperature

- $\mathrm{RH}$ and temperature data within the cavity of double insulated glass

- preliminary measurements of the energy consumption of the $3 \mathrm{D}$ building system

In parallel to ambient measurements, a thermographic camera was used to capture possible relevant thermal bridges, as well as critical details of the Live-Lab assembly, with careful consideration for the region of joints and corners.

\section{Instruments for the Continuous Ambient Monitoring of Thermo-Physical Characteristics}

At the time of the first Live-Lab assembly, a meteorological station was attached to the facility, so as to measure the external climate parameters (wind speed, wind direction, precipitations, temperature and humidity). The meteorological station was linked to a central control station (specifically designed for the research project by SITEL d.o.o. Ljubljana, Slovenia (www.sitel.si)), so as to support the continuous monitoring of climate conditions and the acquisition of relevant data. The position and description of measuring instruments is proposed in Fig. 7.

As a particularity of the Live-Lab facility, an heating source was also taken into account for the cavity between two glass panels (double glazing sections according to Fig. 2). As the hygrothermal properties in the cavity were set as control parameter for the continuous measurements, the heater was set to automatically switch on at the first attainment of the dew point for glass.

In the post-processing stage, based on the collected measurement data, the impact of such a kind of heating source was assessed in terms of sensitivity of the thermal transmission of the 3D facility as a whole. The latter was also assessed in terms of impact on the energy consumption for maintaining a constant indoor temperature for the facility. To optimize the energy consumption of the Live-Lab prototype, solar panels were installed on the roof, to act as an additional external energy source. Electricity for heating or cooling of the facility was thus supplied both from the electricity grid and from the solar panels. Setup instruments, finally, included an air conditioner and a fan, so as to reproduce the typical configuration of residential and commercial buildings. All the above devices and acquired data in time were thus taken into account to assess the energy terms delivered and consumed by the facility, thus assessing the energy balance of the building prototype.

\section{Experimental Results}

In Fig. 8, major outcomes from continuous indoor monitoring of the Live-Lab facility are proposed in terms of temperature and $\mathrm{RH}$ records. Depending on the external climate conditions (Fig. 5b), major efforts were spent to achieve comfortable hygrothermal conditions, in line with conventional human habitation parameters. Careful consideration was spent also for the monitoring of hygrothermal conditions in the glass cavity, where the heater source was installed.

During continuous monitoring and measurements, a slightly higher energy consumption was observed to reach the required indoor conditions. The reason was found in the presence of linear thermal bridges, that were properly detected in their critical details with the support of thermal cameras. As expected, Fig. 9, major temperature scatter and variations were found especially in the region of transition from CLT to glass. 


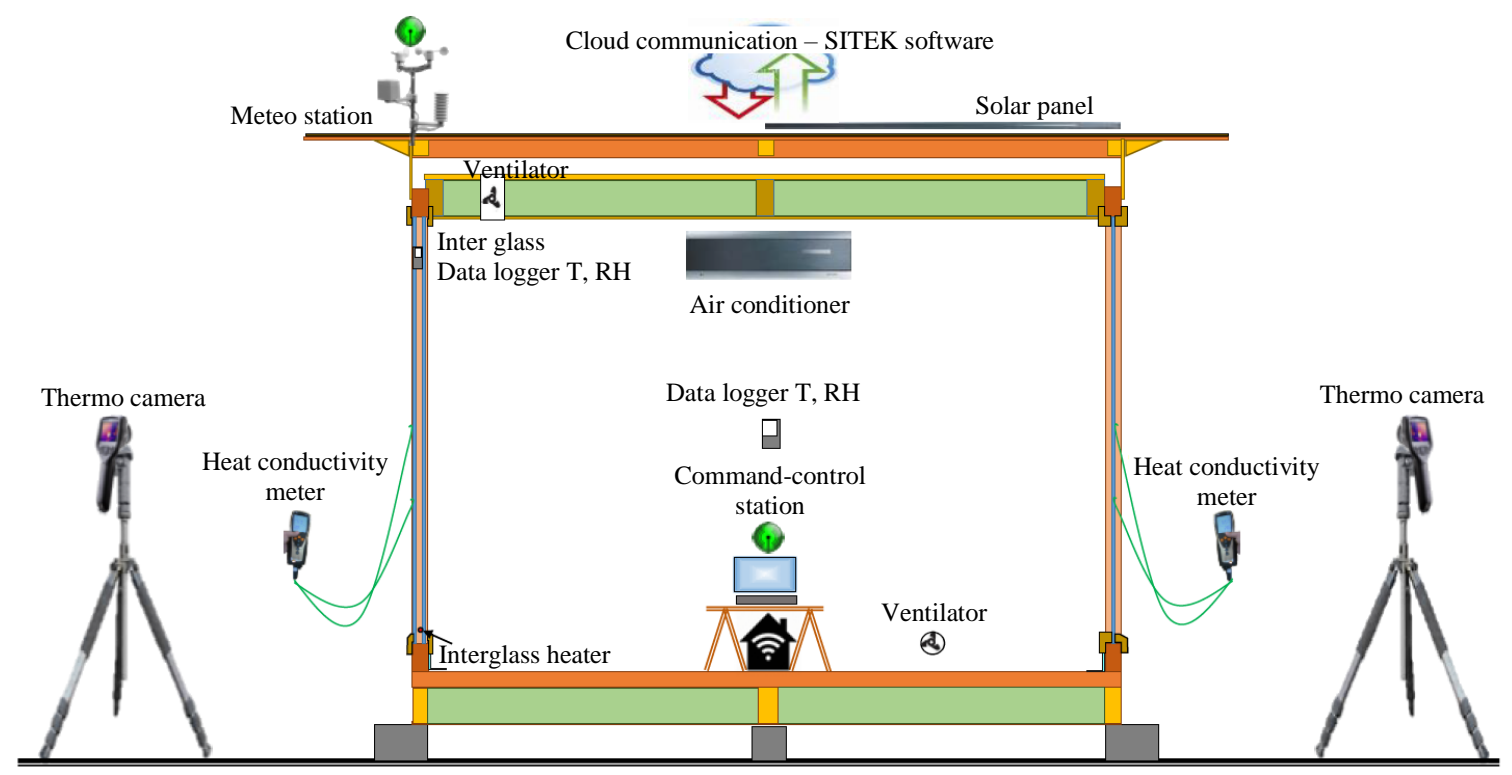

Fig. 7: Instruments and devices in use for the ambient experimental measurements (schematic cross-section)

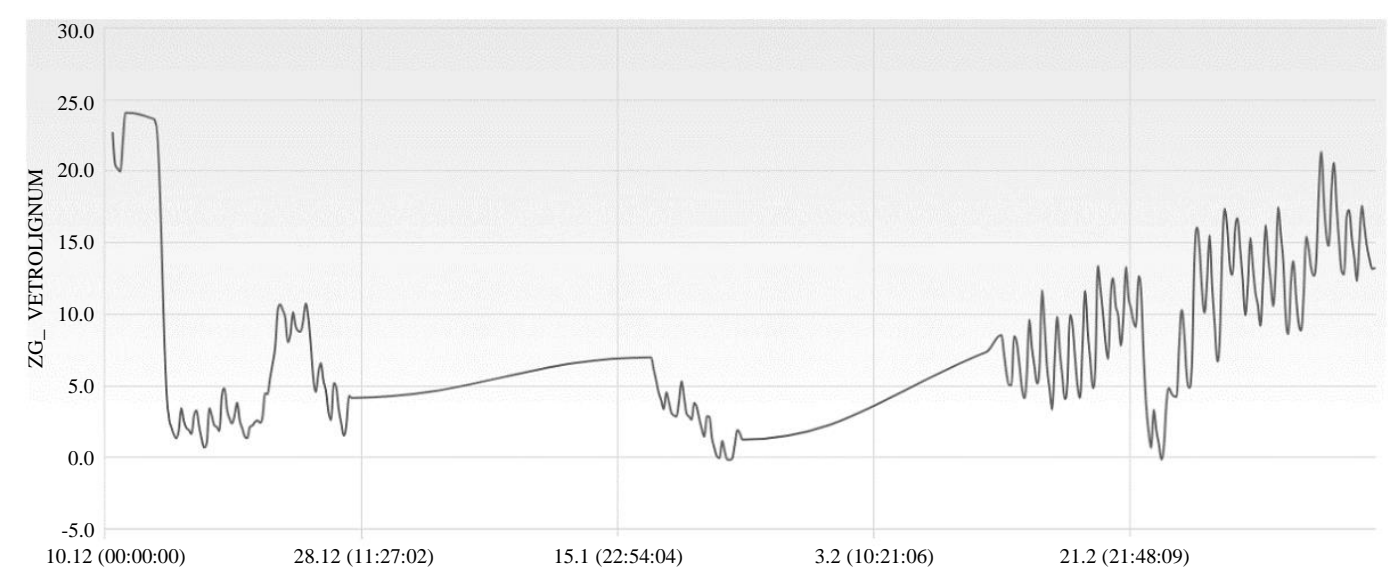

(a)

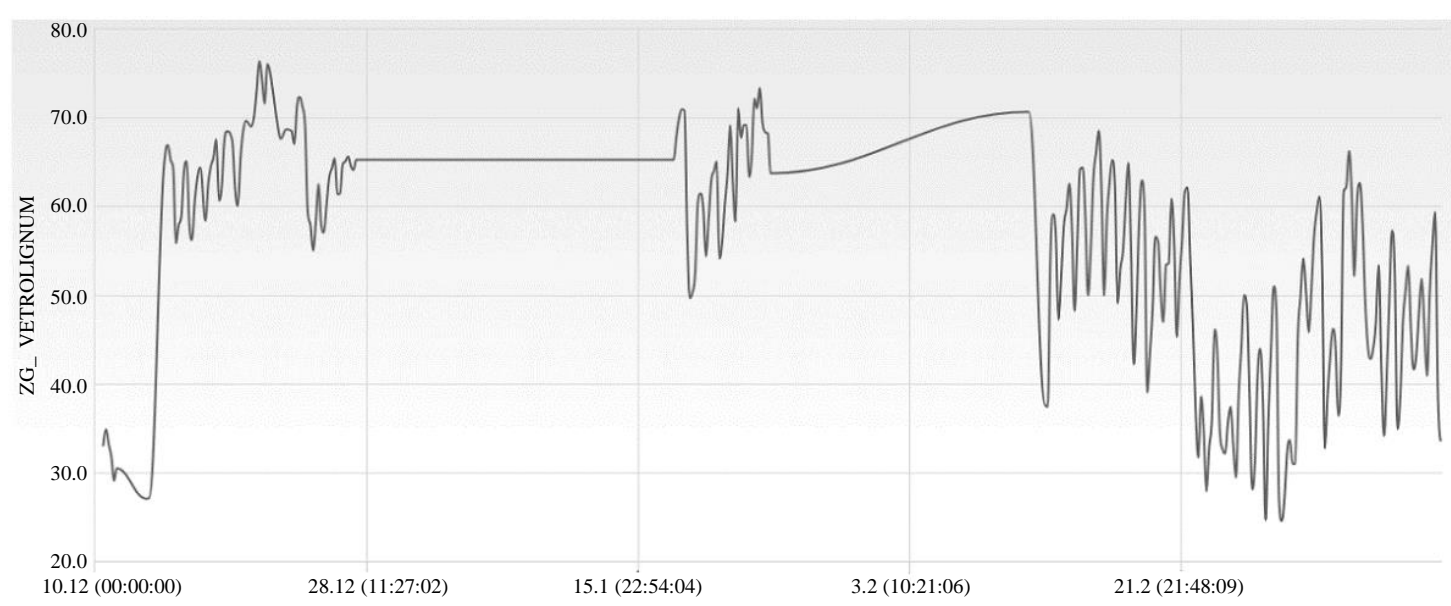

(b)

Fig. 8: Example of Live-Lab ambient measurements from the SITEL control station: (a) temperature and (b) relative humidity 


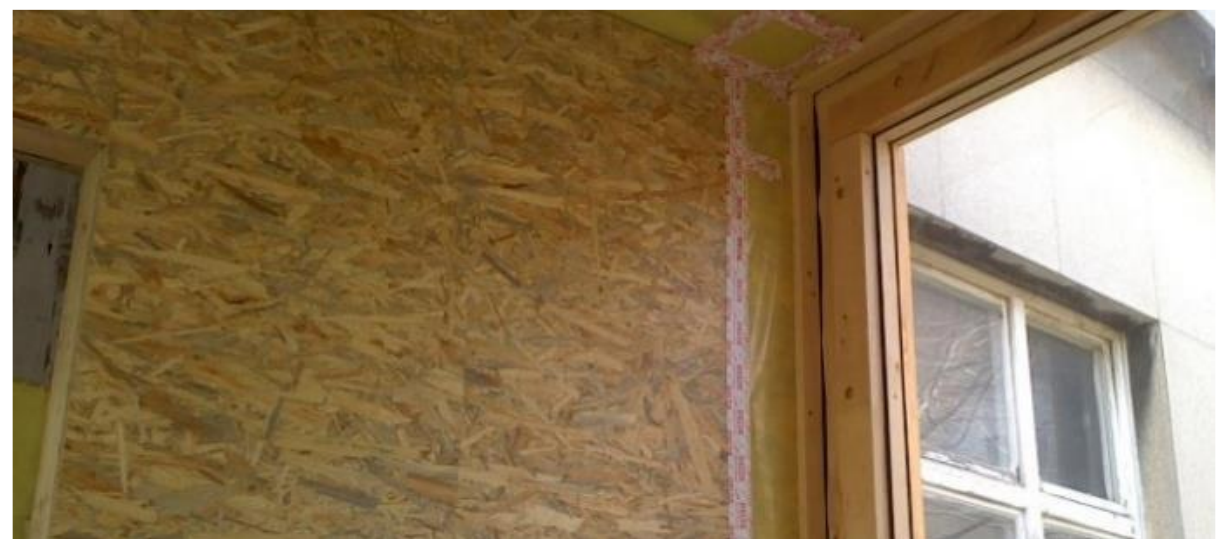

(a)

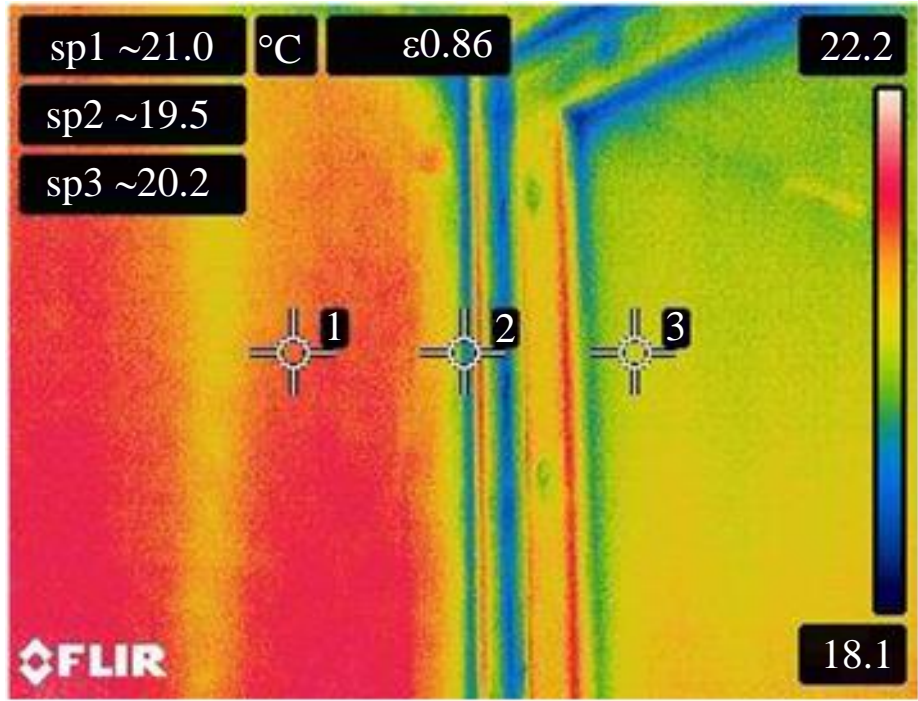

(b)

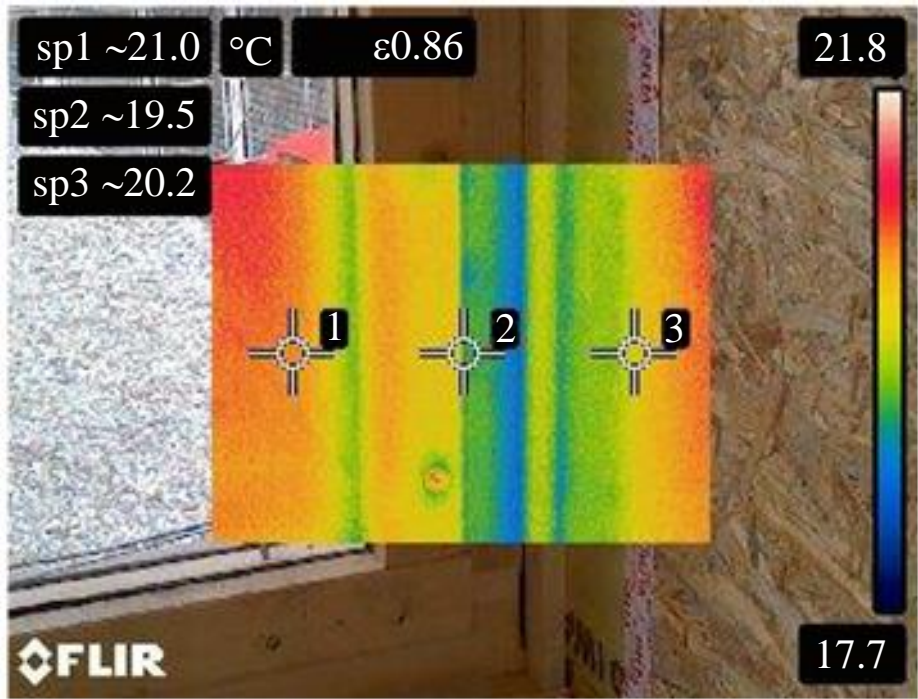

(c)

Fig. 9: Thermal bridges detected by thermal camera acquisitions: (a) top corner layout (indoor), with (b) corresponding temperature field and (c)-(d) bottom corner detail (indoor and outdoor measurements) 


\section{Thermal Numerical Analyses}

\section{Component Assessment}

A first attempt was carried out in the form of thermal numerical analysis of the typical CLT-glass facade element in use for the Live-Lab building (ABAQUS (Simulia, 2019)). Taking advantage of geometrical symmetry of the typical system, the FE modelling was focused on $1 / 4$ th the nominal CLTglass module in Fig. 6.

The use of symmetry restraints allowed to enhance the computational cost of simulations, without affecting the accuracy of estimates in the critical regions.

The reference FE assembly, Fig. 10, hence consisted of a set of 8-node, heat transfer solid elements (DC3D8 type from ABAQUS library) representative of the nominal geometry for:

- The laminated glass sections (double 10.10/1.6 glass panels)

- The interposed air cavity $(s=12.8 \mathrm{~mm})$

- A rubber edge trim facilitating the glass panels to keep their position

- The CLT frame members

- The additional timber purlins providing a slot for the activation of frictional mechanisms along the edges of glass

The thermal performance of the CLT-glass facade module was assessed by evaluating few key performance indicators, such as the overall U-value, the corresponding linear thermal transmittance $\psi$ value and the expected temperature scenario under the imposed gradient $\Delta T$ (for condensation risk assessment), with a focus on the minimum surface temperature on glass $\left(T_{\min }\right)$. The latter, according to Equation (3), is in fact directly responsible of the temperature factor at the internal surface $f_{R s i}$ and thus overall thermal comfort.

The thermal boundary conditions for the FE steadystate simulations, based on EN ISO 10077-2:2017 provisions, were defined as follows:

- Relative Humidity: $50 \%$

- External condition: $T=0^{\circ} \mathrm{C}$, film coefficient (timber and glass) $=23 \mathrm{~W} / \mathrm{m}^{2} \mathrm{~K}$

- Internal condition: $T=20^{\circ} \mathrm{C}$, film coefficient (timber and glass) $=8.02 \mathrm{~W} / \mathrm{m}^{2} \mathrm{~K}$

The thermal performance investigation was hence carried out under steady state conditions, for an imposed thermal gradient $\Delta T=20^{\circ} \mathrm{C}$. Such a selected thermal scenario - besides the recommendations from standards - was found to be well representative of real field measurements available from the Live-Lab (i.e., Fig. 6) and average indoor conditions for a common building.

For FE purposes, the thermal characterization of materials was carried out based on nominal thermophysical parameters provided by design standards or literature references (Table 1). A special care was paid, in the latter case, for the air volume enclosed within the cavity between the laminated glass panels, that was properly described in the form of equivalent conductivity. This means that the interposed cavity is perfectly sealed along the glass edges and can be also extended to the VETROLIGNUM prototype (with frictional contacts with the timber frame, but a continuous flexible rubber to enclose the cavity).

The required surface film and surface radiation surface interactions able to account for the thermal exposure of glass and timber (for both the indoor and outdoor faces) were defined according to literature background for similar structural solutions (Bedon et al., 2018; Sjöström et al., 2020). Along the longitudinal and transversal mid-section of the so assembled FE models, finally, symmetry conditions were accounted to reproduce the thermal performance of $1 / 4$ th model as a part of the full-scale facade element.

Major FE outcomes are proposed in Table 2 in terms of U-total estimates, the corresponding $\Psi$-values and also $\mathrm{max} / \mathrm{min}$ internal temperatures for glass $\left(T_{\text {si,max }}\right.$ and $\left.T_{s i, m i n}\right)$. In addition, Fig. 11 shows the typical temperature distribution in glass and in a portion of timber frame members (corner region), for the reference CLT-glass system.

Based on a more refined assessment of temperature distributions in timber and glass components, in Fig. 11 it can be easily detected the region of glass in which contact with timber modifies its thermal response.

To this aim, Fig. 12a shows the typical temperature distribution in the frame cross-section (CLT members and purlins), while Fig. 12b offers a more detailed representation of temperatures in the thickness of glass. As far as the glass components are in contact with the frame of Fig. 12a, the temperature distribution at the glass edges corresponds to the "Glass edge" plot in Fig. 12b. In the same figure, the $\mathrm{CP} 1, \mathrm{CP} 2$ and $\mathrm{CP} 3$ control points are still representative of temperature distributions in the glass thickness. According to the contour plot of Fig. 11, these $\mathrm{CP} n$ values are selected on the diagonal of glass panel, at a distance of $50 \mathrm{~mm}, 90 \mathrm{~mm}$ and $150 \mathrm{~mm}$ respectively from the corner. 


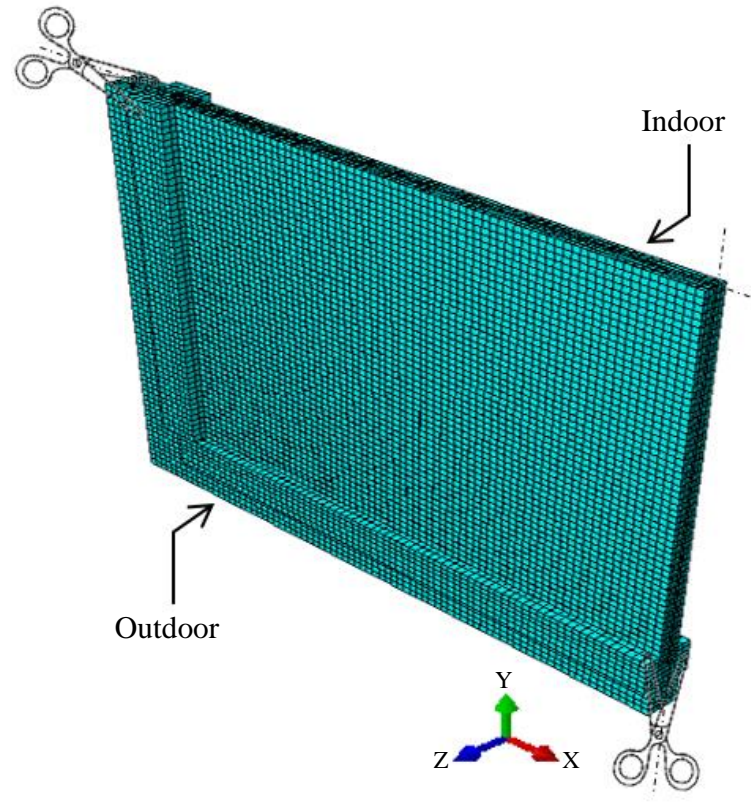

(a)

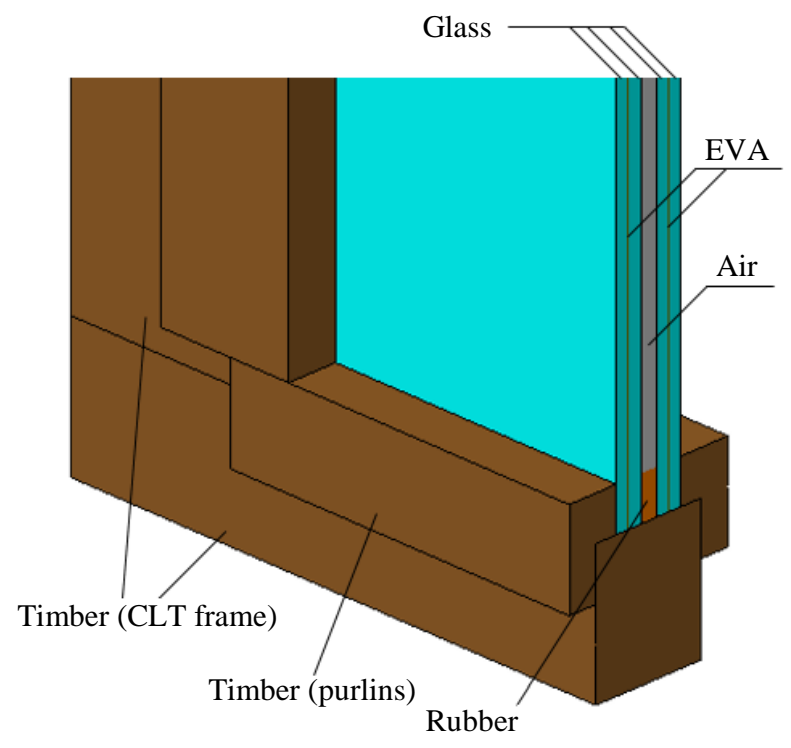

(b)

Fig. 10: FE model for the thermal assessment of full-size CLT-glass facade elements: (a) global assembly (1/4th of the nominal geometry) and (b) detailed view, with hidden mesh (ABAQUS)

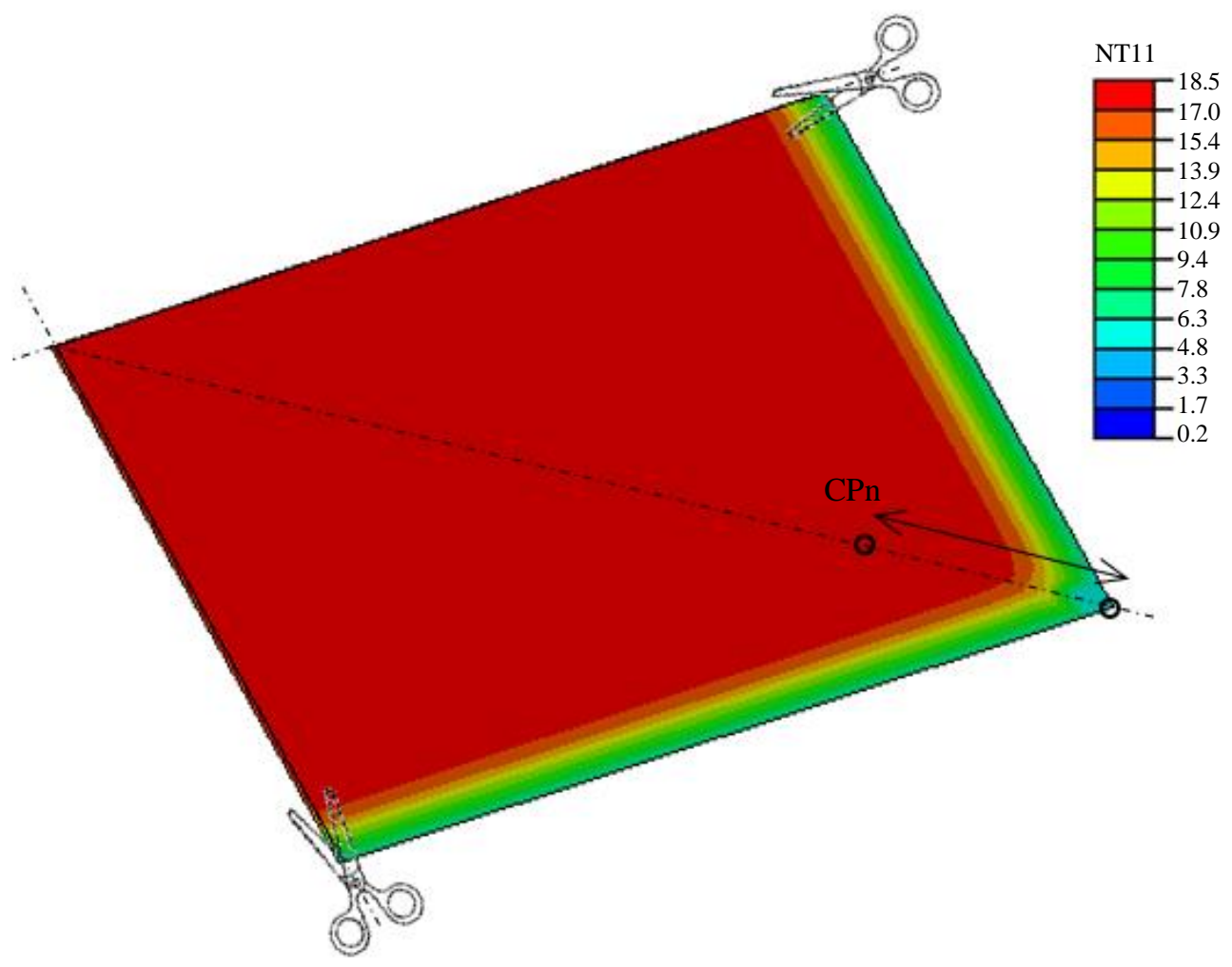

Fig. 11: FE thermal performance assessment of a full-scale CLT-glass facade element (ABAQUS). Expected distribution of temperature in the internal glass panel (external side) (values in ${ }^{\circ} \mathrm{C}$ ) 


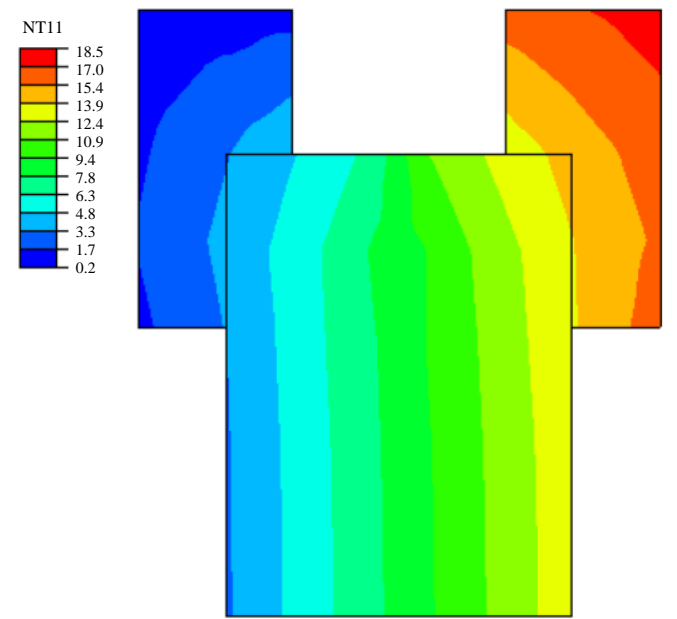

(a)

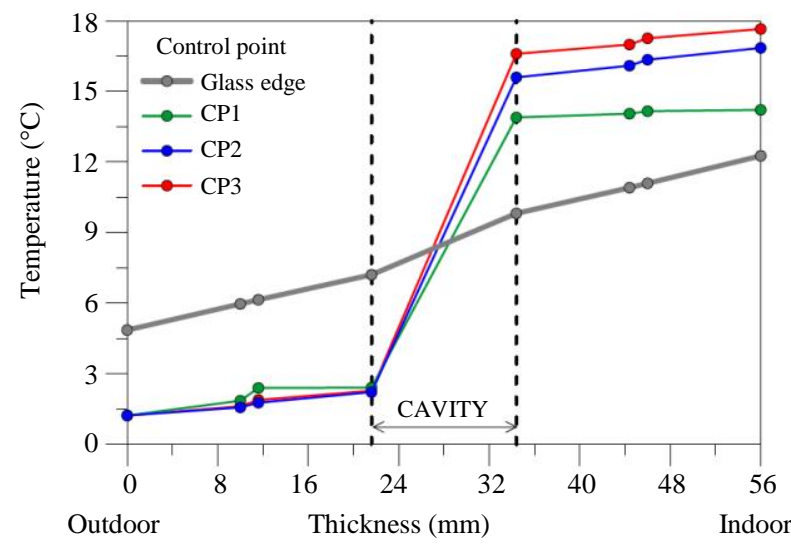

(b)

Fig. 12: FE thermal performance assessment of a full-scale CLT-glass facade element. Temperature distribution: (a) in the frame cross-section and (b) in the thickness of glass panel, with a focus on the corner joint region (ABAQUS, values in ${ }^{\circ} \mathrm{C}$ )

Table 1: Input thermal properties in use for FE modelling in ABAQUS

\begin{tabular}{lllll}
\hline & Component & & \multicolumn{2}{c}{ Interposed cavity } \\
& - & & \\
& Glass & EVA & Timber & Rubber \\
\hline Conductivity $\lambda(\mathrm{W} / \mathrm{mK})$ & 0.8 & 0.19 & 0.3 & 0.1 \\
Emissivity $\varepsilon(-)$ & 0.95 & $/$ & 0.7 & $/$ \\
\hline
\end{tabular}

Table 2: Numerical thermal performance assessment of the CLT-glass facade element (ABAQUS)

\begin{tabular}{ll}
\hline & $\begin{array}{l}\text { Double laminated EVA }(10.10 / 1.6) \\
\text { FE component model }\end{array}$ \\
\hline Uarameter & 1.826 \\
$\psi$-value $\left(\mathrm{W} / \mathrm{m}^{2} \mathrm{~K}\right)$ & 0.5285 \\
Imposed $\Delta \mathrm{T}\left({ }^{\circ} \mathrm{C}\right)$ & 20 \\
$\mathrm{~T}_{\text {si,max }}\left({ }^{\circ} \mathrm{C}\right)$ & 16.60 \\
$\mathrm{~T}_{\text {si,min }}\left({ }^{\circ} \mathrm{C}\right)$ & 9.15 \\
\hline
\end{tabular}

\section{Some First Considerations}

The knowledge of temperature distributions according to Fig. 12b allows to draw some important (even preliminary) considerations for thermal assessment purposes.

To avoid condensation, as known, the minimum surface temperature $\left(T_{\min }\right)$ on the internal face of glass (i.e., inside the cavity volume) needs to be higher than the dew point temperature $\left(T_{d p}\right)$ for air conditions occurring inside the panel, that is:

$$
T_{\min } \geq T_{d p}=f(R H, T)
$$

The minimum measured surface temperature, see Table 2 and Fig. 12b, was calculated in $9.15^{\circ} \mathrm{C}$ (frame region), or higher. According to European standards, the reference $T_{d p}$ value for the examined boundary conditions should be checked based on moke up experiments including the continuous monitoring of temperature and humidity values inside the cavity. A similar approach, for example, was proposed in (Zobec et al., 2002) for a novel curtain wall system with metal frame and represents a key design step for glass envelopes in general, especially with regard to the detailing of framing members and sealants.

Conservatively, the calculation is carried out in this study for the worst conditions in the cavity volume, that is an air temperature of $9^{\circ} \mathrm{C}$ and $\mathrm{RH}=80 \%$. The corresponding $T_{d p}$ is estimated in $5.7^{\circ} \mathrm{C}$ and consequently the examined CLT-glass facade element (even in the critical regions of connection with the timber frame members) suggests an appropriate thermal performance. Its overall behaviour, however, will be further explored in the next stages of the project, with the support of the mock-up registrations.

Another relevant parameter is represented by the minimum surface temperature on the indoor face of glass (i.e., temperature estimates in Fig. 12b, for a position of $56 \mathrm{~mm}$ ). In the latter case, for indoor conditions of $20^{\circ} \mathrm{C}$ and $50 \%$ of Relative Humidity, the recommended reference value is $T_{d p}=6^{\circ} \mathrm{C}$, thus the limit condition is again optimally satisfied. 
Some final considerations cane be spent for the expected temperature factor $f_{R s i}$. Following standard provisions and Equation (3), the calculation of the surface temperature factor should be carried out during the winter season. In addition, the maximum monthly value for the temperature factor should be separately determined, so as to define the minimum value of the overall thermal resistance that a given building envelope should offer to avoid surface condensation risk.

As far as Equation (3) is taken into account for the numerically investigated CLT-glass system of Fig. 12, it is found that:

$f_{R s i}=\frac{T_{s i}-T_{\text {out }}}{T_{\mathrm{int}}-T_{\text {out }}}=0.613$

and the latter is mostly in line with minimum requirements previously recalled in this paper.

\section{Conclusion}

An innovative hybrid structural component composed of CLT frame and laminated glass infill was analyzed in this paper, as a further extension of the extensive experimental programme started in 2006 within the framework of the Croatian VETROLIGNUM.

The design concept, as shown, was originally developed to take advantage of the mechanical interaction of Cross-Laminated Timber (CLT) and glass load-bearing members, without sealing or glued glass-to-timber surfaces. Facade elements, as known, are however required to satisfy multiple performance parameters, as a part of complex buildings. Besides the assumption that the basic components should be optimally designed to offer enhanced mechanical properties and efficiency for the building itself, these systems should be also energy efficient, durable, including high lightening comfort and optimal thermal performances.

In the paper, a set of brief guidelines for the optimal structural design of CLT-glass hybrid facade elements was first presented. Major advantage was taken from past experimental investigations of literature for the same design concept, when subjected to lateral loads such as earthquakes or wind loads.

A special focus was successively dedicated to the thermal performance assessment of the same facade module, under ordinary operational conditions. At the component level, detailed Finite Element numerical models were developed to assess the typical thermal response. Major advantage was taken from continuous ambient records of environmental and thermal comfort parameters, from a mock-up building ("Live-Lab" facility in Zagreb). The preliminary numerical results showed that the CLT-glass hybrid facade system offers stable thermal performances, in line with national standards and European requirements. At the same time, however, the region of corner joints was found to be critical. In the next phase of the research study, accordingly, the connection details and the potentiality of alternative solutions (for sealing and/or shading) will be thus further elaborated.

\section{Acknowledgement}

The herein reported research study is funded by The Croatian Science Foundation (Project no. IP-2016-063811 VETROLIGNUM - "Prototype of multipurpose composite timber-load bearing glass panel", coordinator Prof. Vlatka Rajčić, University of Zagreb, Croatia).

\section{Funding Information}

The Croatian Science Foundation is gratefully acknowledged for providing the financial support for the VETROLIGNUM research project.

\section{Author's Contributions}

This paper results from a joint collaboration between all the involved authors.

\section{Ethics}

The authors declare there are no conflicts of interests.

\section{References}

Aldawoud, A., 2017. Assessing the energy performance of modern glass facade systems. MATEC Web Conf., 120: 08001-08001.

DOI: $10.1051 /$ matecconf/201712008001

Antolinc, D., 2013. Uporaba steklenih panelov za potresno varno gradnjo objektov [Use of laminated glass panels for earthquake resistant building design (in Croatian)]. Ph.D. Thesis, University of Ljubljana.

Bedon, C., 2017. Structural glass systems under fire: Overview of design issues, experimental research and developments. Adv. Civil Eng.

DOI: $10.1155 / 2017 / 2120570$

Bedon, C. and C. Louter, 2018. Thermo-mechanical numerical modelling of structural glass under fire Preliminary considerations and comparisons. Proceedings of the Challenging Glass - International Conference on Architectural and Structural Applications of Glass, May 11-13, Delft University, Belgium, pp: 513-524. DOI: 10.7480/cgc.6.2173

Bedon, C. and M. Santarsiero, 2018. Transparency in structural glass systems via mechanical, adhesive and laminated connections - existing research and developments. Adv. Eng. Mater. DOI: 10.1002/adem.201700815 
Bedon, C., C. Pascual, A.L. Navarro and M. Overend, 2018. Thermo-mechanical investigation of novel GFRP-glass sandwich facade components. Challeng. Glass Proc., 6: 501-512.

DOI: $10.7480 /$ cgc.6.2172

Bejtka, I., 2011. Cross (CLT) and Diagonal (DLT) Laminated Timber as Innovative Material for Beam Elements. 1st Edn., KIT Scientific Publishing, Karlsruhe, ISBN-10: 3866446047, pp: 134

Ber, B., M. Premrov, I. Sustersic and B. Dujic, 2013. Innovative earthquake resistant timber-glass buildings. Natural Sci., 5: 63-71. DOI: $10.4236 /$ ns.2013.58A1008

Blyberg, L., M. Lang, K. Lundstedt, M. Schander and E. Serrano et al., 2014. Glass, timber and adhesive joints - innovative load bearing building components. Constr. Build. Mater., 55: 470-478.

Buildings Department, 2018. Code of practice for the structural use of glass.

CEN/TC 250, 2019a. prCEN/TS xxxx-1: 2019 - In-plane loaded glass components. CEN - European Committee for Standardization, Brussels, Belgium.

CEN/TC 250, 2019b. prCEN/TS xxxx-2:2019 - Out of-plane loaded glass components. CEN European Committee for Standardization, Brussels, Belgium.

CNR-DT 210/2013, 2013. Istruzioni per la Progettazione. l'Esecuzione ed il Controllo di costruzioni con Elementi Strutturali in Vetro [Guideline for design, execution and control of constructions made of structural glass elements (in Italian)]. National Research Council (CNR), Roma, Italy. www.cnr.it

Cruz, P. and J. Pequeno, 2008. Timber-glass composite beams: Mechanical behaviour and architectural solutions. Challeng. Glass Proc.

EN 338, 2016. Structural timber - strength classes. European Committee for Standardization (CEN), Brussels, Belgium.

EN 1995-1-1, 2004. Eurocode 5: Design of timber structures - Part 1-1: General - Common rules and rules for buildings. CEN - European Committee for Standardization, Brussels, Belgium.

EN 12543-2, 2004. Glass in building - Laminated glass and laminated safety glass - Part 2: Laminated safety glass. CEN - European Committee for Standardization, Brussels, Belgium.

EN ISO 13788. Hygrothermal performance of building components and building elements - Internal surface temperature to avoid critical surface humidity and interstitial condensation - Calculation methods. International Organization for Standardization (ISO), Brussels, Belgium.
EN ISO 10077-2. Thermal performance of windows, doors and shutters - Calculation of thermal transmittance - Numerical methods for frames. CEN - European Committee for Standardization, Brussels, Belgium.

EU 2010/31. European Commission - Directive 2010/31/EU of the European parliament and of the Council.

Feldmann, M. and P. Di Biase, 2018. The CEN-TS "structural glass - design and construction rules" as pre-standard for the Eurocode. ce/papers, 2(5-6): 7180. Special Issue: Engineered Transparency 2018 Glass in Architectural and Structural Engineering.

Feldmann, M., R. Kasper, K. Langosch, S. Dimova and A.V. Pinto et al., 2014. Guidance for European structural design of glass components: Support to the implementation, harmonization and further development of the Eurocodes. Report EUR 26439Joint Research Centre-Institute for the Protection and Security of the Citizen.

Jeleč, M., D. Varevac and V. Rajčić, 2018. Križno lamelirano drvo (CLT) - pregled stanja područja [Cross Laminated Timber (CLT) - A state of the art report], Građevinar, 70: 75-95.

Kalamee, T., 2006. Critical values for the temperature factor to assess thermal bridges. Proc. Estonian Acad. Sci. Eng., 12: 218-229.

Kozlowski, M., C. Bedon and D. Honfi, 2018. Numerical analysis and 1D/2D sensitivity study for monolithic and laminated structural glass elements under thermal exposure. Materials, 11: 1447-1447. DOI: $10.3390 / \mathrm{ma} 11081447$

Neubauer, G., 2011. Entwicklung und Bemessung von statisch wirksamen Holz-GlasVerbundkonstruktionen zum Einsatz im Fassadenbereich [Development and dimensioning of structurally effective wood-glass composites for use in the facade sector (in German)]. Ph.D. Thesis, University of Technology TU Wien.

Planas, C., E. Cuerva and P. Alavedra, 2018. Effects of the type of façade on the energy performance of office buildings representative of the city of Barcelona. Ains Shams Eng. J., 9: 3325-3334

prEN 13474-2 Glass in building - design of glass panes Part 2: Design for uniformly distributed loads. CEN - European Committee for Standardization, Brussels, Belgium.

Premrov, M., M. Zlatinek and A. Štrukelj, 2014. Experimental analysis of load-bearing timber-glass I-beam. Constr. Unique Build. Struct., 4: 11-20.

Rajčić, V. and R. Žarnić, 2012. Seismic response of timber frames with laminated glass infill. CIBW18/45-15-4, Växjo, Sweden. 
Rodacki, K., M. Tekieli and K. Furtak, 2019. Contactless optical measurement methods for glass beams and composite timber-glass I-beams. Measurement, 134: 662-672.

Simulia, 2019. ABAQUS v.6.14 computer software and online documentation. Dassault Systems, Providence, RI, USA.

Sjöström, J., M. Kozlowski, D. Honfi, D. Lange and J. Albrektsson et al., 2020. Fire resistance testing of a timber-glass composite beam. Int. J. Structural Glass Adv. Mater. Res.

Zanor, D., J. Pretty, J. Morrison and S.K. Todorovic, 2005. Environmental and macroeconomic impact assessment of different development scenarios to organic and low-input farming in Croatia. Technical Report, ID 26404, University of Essex, Colchester.
Žarnić, R., V. Rajčić and M. Kržan, 2020. Response of laminated glass-CLT structural components to reverse-cyclic lateral loading. Constr. Build. Mater., 235: 117509-117509.

Zobec, M., M. Colombari, F. Peron and P. Romagnoni, 2002. Hot-box tests for building envelope condensation assessment. Proceedings of 23rd AIVC and EPIC Conference (in Conjunction with 3rd European Conference on Energy Performance and Indoor Climate in Buildings) - Energy Efficient and Healthy Buildings in Sustainable Cities, Oct. 23-26, Lyon, France. 